
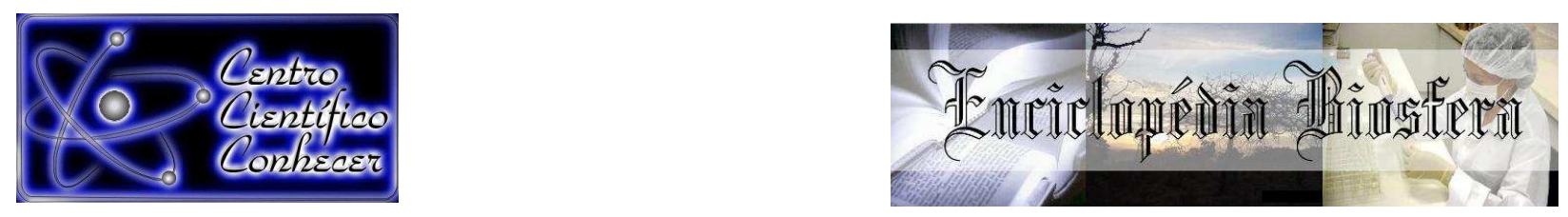

\title{
ENTEROPARASITAS VEICULADOS EM FOLHAS DE ALFACES (Lactuca sativa) COMERCIALIZADAS NA FEIRA LIVRE DA CIDADE DE GOVERNADOR VALADARES, MINAS GERAIS
}

\begin{abstract}
Vânia Guimarães da Silva ${ }^{1}$; Gabriel Camargos dos Santos ${ }^{2}$; Vitoria Maryana da Silva Ferreira

${ }^{1}$ Professora Mestre do Curso Técnico em Meio Ambiente do Instituto Federal de Minas Gerais, campus Governador Valadares (vania.guimaraes@ifmg.edu.br).

${ }^{2}$ Alunos do $3^{\circ}$ ano do Curso Técnico Integrado em Meio Ambiente do Instituto

Federal de Minas Gerais, campus Governador Valadares.
\end{abstract}

Recebido em: 08/04/2017 - Aprovado em: 10/06/2017 - Publicado em: 20/06/2017 DOI: 10.18677/EnciBio_2017A111

\begin{abstract}
RESUMO
O consumo de hortaliças na forma crua garante um aproveitamento maior de nutrientes, sendo também o meio de transmissão mais comum de doenças enteroparasitárias. Esse estudo objetivou avaliar a frequência de parasitas em alfaces (Lactuca sativa) comercializadas em quatro bancas na feira livre de Governador Valadares-MG. Foram analisadas vinte amostras, que passaram por um processo de lavagem, a água da lavagem foi centrifugada e o seu sedimento foi analisado. Ao final das analises, verificou-se que $90 \%$ das amostras estavam contaminadas por enteroparasitas, como Schistosoma mansoni, Ancilostomo sp, Ascarisumbricoides, Trichuris trichiuria, larvas e ovos não identificados e cistos de protozoários, como Entamoeba histolytica e Giardialamblia. A presença de protozoários nas amostras confirma que no cultivo e/ou distribuição ocorreu à contaminação das alfaces. As fontes de contaminação das hortaliças se destacam a água de irrigação, o solo adubado por esterco animal, a precária higienizaçãosanitária e todas as etapas de manipulação.
\end{abstract}

PALAVRAS-CHAVE: Alface, contaminação, parasitas.

\section{ENTEROPARASITES VEICULATED IN LEAVES OF ALFACES (Lactuca sativa) COMMERCIALIZED IN THE FREE FAIR OF THE CITY OF GOVERNADOR VALADARES, MINAS GERAIS}

\begin{abstract}
The consumption of vegetables in the raw form guarantees a greater use of nutrients, being also the most common means of transmission of enteroparasitary diseases. This study aimed to evaluate the frequency of parasites in environments (Lactuca sativa) marketed in four stands on the day off of Governador Valadares-MG. Twenty samples were analyzed, which underwent a washing process, washing water was centrifuged and its sediment was analyzed. At the end of the analyzes, $90 \%$ of the samples contaminated by enteroparasites, such as Schistosoma mansoni,
\end{abstract}


Ancylostoma sp., Ascaris lumbricoides, Trichuris trichiuria, unidentified larvae and eggs and protozoan cysts, such as Entamoeba histolytica and Giardia lamblia were found. The presence of protozoa in the samples confirms that no cultivation and / or distribution occurred contamination of lettuces. As the sources of contamination of vegetables stand out in irrigation water, or in soil fertilized by animal manure, a precarious hygiene sanitary and all stages of manipulation.

KEYWORDS: Contamination, lettuce, parasites.

\section{INTRODUÇÃO}

O apelo por hortaliças no cardápio das refeições diárias é devido ao seu alto teor de vitaminas, fibras e minerais. Consideradas alimentos reguladores, as hortaliças são fundamentais para fazer o organismo funcionar de maneira adequada e harmônica (EMBRAPA, 2012). Frescos, saudáveis, nutritivos e de baixo custo, as hortaliças são encontradas em todos os tipos de estabelecimentos que comercializam alimentos, como supermercados, sacolões e feiras livres.

De acordo com RODRIGUES, (2012), a melhor maneira de obter maior aproveitamento de nutrientes das hortaliças é através da forma crua. A alface é uma cultura plantada e consumida em todo o território brasileiro, não obstante as diferenças climáticas e os hábitos de consumo (COSTA \& SALA, 2005). A alface é considerada a hortaliça mais consumida no Brasil, sendo utilizada em pratos decorativos, lanches, acompanhamentos e em variadas saladas. Essa hortaliça faz parte do hábito alimentar de toda população, podendo ser produzida de modo tradicional, não orgânico, com presença de agrotóxicos, ou também pode ser cultivada por meio de métodos agrícolas denominados orgânicos, que por não possuir agrotóxicos e pesticidas são rotulados como mais saudáveis, aumentando assim o seu mercado consumidor (ACOSTA \& DUARTE, 2005).

As folhas de alface estão relacionadas à veiculação de algum tipo de formas parasitárias contaminantes para o homem, às vezes com índices baixos ou altos, no caso desses podendo levar a pessoa que ingeriu a problemas de saúde. Todo cuidado é necessário durante o processo do cultivo e no transporte para que nenhum agente etiológico entre em contato e contamine a hortaliça (XAVIER, 2009).

Com base em outros artigos, os parasitas com um grau frequente de identificação nas pesquisas são a Giadia lamblia, um protozoário que durante o processo de infecção impede a absorção de lipídeos e vitaminas lipossolúveis. Sua transmissão se da na ingestão dos cistos de Giardia presentes nas fezes de seres humanos contaminados e portadores do parasita. Esta ingestão pode ser de forma direta, ou seja, através do contato com as mãos e depois na boca ou na pele, consumindo alimentos ou água contaminada. A Entamoeba histolytica que tem como mecanismo de transmissão a ingestão de cistos maduros nos alimentos sólidos e líquido . Este protozoário se instala no intestino humano em sua forma adulta, e passa a coloniza a parede do intestino, podendo ter um comportamento comensal, ou seja, se alimenta dos nutrientes ingeridos pelo hospedeiro, ou um comportamento agressivo, em que a Entamoeba histolytica invade a parede do cólon provocando inflamações intestinais ou caindo na corrente sanguínea e indo se alojar em outro órgão como cérebro, pulmão ou fígado (NEVES 2004).

Grande parte das hortaliças é contaminada através da água de irrigação sem tratamento, sendo esta proveniente de minas e córregos, que pode estar contaminado por fezes humanas (MAROUELLI et al., 2014). Segundo ACOSTA \& 
DUARTE (2005), doenças parasitárias são fatores em que seus maiores contaminadores provêm da transmissão ambiental através da água contaminada e dos cultivos alimentícios. Para isso, a utilização de água potável no processo de irrigação da alface é de extrema importância, pois garante que a água esteja livre de substâncias e organismos que trazem riscos a saúde. Cuidados com o tipo de fertilizante e adubo utilizado no cultivo também devem ser levados em consideração em relação a possível contaminação da alface. Como adubos provenientes de fezes principalmente de equinos e bovinos, que em sua composição há múltiplos tipos de bactérias e protozoários.

O consumidor, por sua vez, não consegue avaliar visualmente todos os atributos que garante um alimento seguro no momento da compra. Os níveis de contaminação microbiológica são invisíveis e só podem ser determinados por meio de testes laboratoriais (HENRIQUE et al., 2014). Como não é garantia que o produto que irá comprar esteja em boas condições para o consumo e sem risco à saúde, há procedimentos caseiros em que o comprador pode efetuar antes de consumi-lo da forma crua, que eliminam boa parte das chances de se ingerir qualquer microrganismo. Portanto, uma lavagem na alface com a solução de ácido etanoico, popularmente conhecido como vinagre, ou o uso de uma pequena dose de hipoclorito de sódio em uma solução com água, sendo lavadas em seguida por água potável, são métodos que reduzem a presença de contaminantes na hortaliça (SILVA et al., 2016).

A produção de alimentos deve seguir práticas que propiciem a chegada dos produtos ao consumidor com boa qualidade, livres de contaminação, tanto para os que são produzidos de forma convencional quanto orgânica (ARBOS et al, 2010). Alguns meios para garantir a higiene dos alimentos antes de ir para o comércio, de acordo com NOLLA \& CANTOS (2005), é a realização de programas de educação para os responsáveis pela manipulação dos alimentos e um fortalecimento no sistema de vigilância sanitária para fiscalização de alimentos oferecidos para a população, incluindo uma legislação adequada. De acordo com ARBOS (2010) existe possibilidade de alimentos orgânicos ter risco aumentado de contaminação biológica e parasitária devido a sua forma de adubação.

Logo, a proposta do presente artigo teve como intuito avaliar quais enteroparasitas são veiculados nas folhas de alface comercializadas em quatro barracas distintas que participam da feira livre na região do centro da cidade de Governador Valadares, juntamente com a identificação dos organismos enteroparasitários.

\section{MATERIAL E MÉTODOS}

Governador Valadares é um município localizado no estado de Minas Gerias, ocupando uma área de $2.342,319 \mathrm{~km}^{2}$, sendo que $24,4 \mathrm{~km}^{2}$ estão em perímetro urbano e sua população foi estimada em 279.665 habitantes conforme - IBGE em 2016. A cidade é banhada pelo Rio Doce, o responsável pelo fornecimento de água à maior parte da cidade. Vale ressaltar que nessa cidade em todas as manhãs de domingo é realizado nas ruas paralelas ao Mercado Municipal uma feira livre, conhecida popularmente como feira livre do Mercado Municipal, onde são vendidas vegetais, roupas, frutas, carnes, peças aleatórias de eletrônicos como também de bicicletas, entre outros, além de shows proporcionados por artistas de rua (GOVERNADOR VALADARES, 2015). 
Inicialmente foi realizada uma pesquisa na feira livre do Mercado Municipal na cidade de Governador Valadares, com a finalidade de identificar as bancas que comercializavam a alface lisa (Lactuca sativa L.). No período da última semana de agosto à primeira semana de outubro, foram coletadas 20 amostras ao todo, sendo que a cada domingo foi recolhida uma amostra das quatro bancas selecionadas pela pesquisa inicial, de modo que após a compra fossem armazenadas em sacolas plásticas estéreis, cada qual com sua identificação de origem, mantidas em refrigeração até serem encaminhadas no dia seguinte ao laboratório do IFMGCampus Governador Valadares. As amostras recolhidas foram constituídas por um pé inteiro de alface independente do seu tamanho e peso.

Com uso de luvas de látex descartáveis, da marca Descarpack, em todo o procedimento, as folhas pútridas e o talo foram descartados e as folhas em boas condições colocadas em bacia biopratica onde foi realizada a lavagem. Utilizando a técnica descrita por OLIVEIRA \& GERMANO (1992) foi usada solução para a lavagem das folhas de uma amostra é uma mistura de $500 \mathrm{ml}$ de solução fisiológica com 2,5 mL de detergente neutro. De acordo com o método de Lutz (1919) após a lavagem, filtrou-se a água para o béquer por meio de funil analítico utilizando gaze esterilizada para a retirada de dejetos. A solução contida no béquer foi homogeneizada utilizando uma haste de alumínio, em seguida, mediram-se $12 \mathrm{~mL}$ para cada um dos oito tubos cônicos presentes na centrifugadora, totalizando $96 \mathrm{~mL}$ centrifugadas a 2500 rotações por minuto, durante 10 minutos, para cada amostra.

A solução contida no tubo, depois de centrifugada, ficou divida em: líquido sobrenadante e matéria sedimentada. O sobrenadante foi descartado e fazendo-se uso da haste de alumínio, a matéria sedimentada foi transferida para um erlenmeyer. Esse processo se repetiu para cada um dos oito tubos, formando uma solução concentrada de matéria para ser analisada microscopicamente. Com uma pipeta pasteur foi colocado numa lâmina duas gotas do material sedimentado e uma gota de lugol a $1 \%$, para cada amostra foi utilizada 3 lâminas, totalizando 60 lâminas ao final. Todas as lâminas foram analisadas no microscópio óptico, Nova Optical System, com o aumento frequente de $40 \mathrm{x}$ e ao identificar algum enteroparasita, de 100x (NEVES, 2004).

\section{RESULTADOS E DISCUSSÃO}

Em meio as 20 amostras de alface (Lactuca sativa) recolhidas da feira livre de Governador Valadares, $90 \%$ apresentaram a presença de algum tipo de contaminante, destes $72,2 \%$ são monoinfectantes, ou seja, apresentaram apenas um tipo de contaminante por amostra, e 27,8\% são multiplainfectantes, presença de mais de um contaminante por amostra (Tabela 1). SILVA \& GONTIJO, (2012) em pesquisa realizada na cidade de Gurupi - Tocantins encontraram 60\% de contaminação em suas amostras, mostrando resultado inferior ao da presente pesquisa. 
TABELA 1: Resultados obtidos através da pesquisa realizada em feiras livres na cidade de Governador Valadares (MG) no período de agosto a outubro de 2016.

\begin{tabular}{cccc}
\hline $\begin{array}{c}\mathbf{N}^{\circ} \text { de amostra } \\
\text { positivas }\end{array}$ & Frequência (\%) & $\begin{array}{c}\text { Monoinfecção } \\
(\%)\end{array}$ & $\begin{array}{c}\text { Multiplainfecção } \\
(\%)\end{array}$ \\
\hline 18 & 90 & 72,2 & 27,8 \\
\hline Fonte: Dados da pesquisa. & & &
\end{tabular}

Dentre os contaminantes constam-se cistos de protozoários e ovos de helmintos. Sendo que os cistos se distinguiram em Entamoeba histolytica (Shaudinn, 1903) e Giardia lamblia (Leeuwenhoek, 1681), com uma frequência de $65 \%$ e $15 \%$ respectivamente e os ovos de helmintos em Schistosoma mansoni (Sambom, 1907), Ancylostoma duodenale (Dubini, 1843), Ascaris lumbricoides (Linnaeus, 1758) e Trichuris trichiuria (Roederer, 1782; Schrank, 1788), com frequência de $10 \%, 15 \%, 5 \%$ e $5 \%$ respectivamente. Além disso, detectou-se partes de artrópodes e algas em todas as amostras, como também larvas e ovos não identificados, estes apresentando $10 \%$ de frequência. Todos os dados em detalhes constam na tabela abaixo (Tabela 2).

TABELA 2: Frequência de enteroparasitas encontrados em amostras $(n=20)$ de alface (Lactuca sativa) em feiras livres na cidade de Governador Valadares (MG) no período de agosto a outubro de 2016.

\begin{tabular}{lcc}
\hline Enteropararasitas & $\mathbf{N}^{\circ}$ de amostra & Frequência (\%) \\
\hline Cisto de Entamoeba histolytica & 13 & 65 \\
Cisto da Giardia lamblia & 3 & 15 \\
Larvas não identificadas & 2 & 10 \\
Ovos de Schistosoma mansoni & 2 & 10 \\
Ovos de Ancylostoma sp & 3 & 15 \\
Ovos de Ascaris lumbricoides & 1 & 5 \\
Ovos de Trichuris trichiuria & 1 & 5 \\
Ovos não identificados & 2 & 10 \\
& & \\
\hline
\end{tabular}

Estudo similar realizado por LUZ et al. (2012) em feiras livres na região da Grande Natal, Rio grande do Norte apontou uma frequência de $93 \%$ das amostras $(\mathrm{n}=45)$ com algum tipo de contaminante. Detectou-se Entamoeba histolytica $(73,3 \%)$, Giardia lamblia (80\%), Ascaris lumbricoides (25\%), Endolimax nana (20\%), Strongyloides stercoralis (25\%), Entamoeba coli (25\%) e Ancylostoma spp. (20\%).

Outrossim, ALVES et al. (2012) analisaram 45 amostras de alfaces-crespas (Lactuca sativa L.) de plantio convencional, adquiridas em três redes de supermercados na cidade de Cuiabá - MT e obtiveram como resultado $66,7 \%$ das amostras contaminadas por protozoários e helmintos, dentre estes Ascaris $s p$. $(36,9 \%)$, Ancilostomídeos (18,7\%), larvas de outros nematoides $(21,6 \%)$, trofozoítos de Balantidium sp. (12,6\%) e cistos de Entamoeba sp. (5,5\%). Já os estudos de ENCICLOPÉDIA BIOSFERA, Centro Científico Conhecer - Goiânia, v.14 n.25; p. $1347 \quad 2017$ 
FREITAS et al., (2004) no município de Campo Mourão, Estado do Paraná apontou que $58,7 \%$ das amostras $(n=75)$ de feiras livres apresentavam contaminação, Ascaris spp. (13,6\%), Strongyloides spp. (11,4\%), Entamoeba spp. (47,7\%), Ancylostoma spp. (9,1\%), Taenia spp. (2,3\%), Fasciola hepatica $(6,8 \%)$ e Trichuris $\operatorname{spp}(9,1 \%)$. Analogamente com a presente pesquisa houve a predominância de Entamoeba spp. (47,7\%). Não obstante, o estudo de SANTOS et al. (2009) em feiras livres no município de Salvador-BA também apresentou maior predominância de Entamoeba spp. (60\%) em 15 amostras analisadas.

Analisando a contaminação de alfaces comercializados em feira livre e restaurantes na cidade do Rio de Janeiro, PIRES et al. (2014) observaram que 70\% ds amostras apresentavam-se contaminadas por parasitas, sendo que a maior contaminação foi encontrada nas amostras comercializadas no varejo in natura, demonstrando $90 \%$ de contaminação por estruturas parasitárias, já as alfaces comercializadas em restaurante $30 \%$ apresentavam contaminação por parasitas. Pode-se perceber que os cuidados com os alimentos consumidos crus devem ser minuciosos para garantir melhor qualidade dos alimentos e evitando que a contaminação chegue ao consumidor.

SOARES \& CANTOS (2006), na cidade de Florianópolis-SC, em 250 amostras de alface observaram a presença de $76 \%$ de Entamoeba, $12,4 \%$ de Giardia spp, 20,8\% de Blastocystis hominis, 12,4\% de Endolimax nana, 8,8\% de Ancilostomídeos, 4,8\% de Strongyloides ssp., 4,4\% de Trichostrongylus spp., 0,8\% de Toxacara canis, $1,6 \%$ de Ascaris lumbricoides, 0,8\% de Hymenolepis nana, 0,4\% de Enterobius vermiculares e $0 \%$ Trichiuris trichiura. Neste estudo também prevaleceu a Entamoeba como o enteroparasita de maior frequência. Já no trabalho de BELINELO et al. (2009), na cidade de São Mateus-ES, em 140 amostras de alface, foram encontrados, $23 \%$ de trofozoítos de Entamoeba histolytica, $23 \%$ de cistos de Entamoeba histolytica, 14\% de cistos de Giardia lamblia, 1\% de larvas de Nematódeos, 7\% de Ascaris spp., 4\% de Ancylostoma spp., 6\% de Trichuris spp., $3 \%$ Taenia spp, sendo o de maior prevalência os cistos e trofozoitos de Entamoeba spp. Diferente da presente pesquisa, além dos cistos de Entamoeba ssp. foram encontrados trofozoitos obtendo-se uma predominância juntamente com os cistos no estudo de BELINELO et al. (2009).

FARIA et al. (2008) na cidade de Ipatinga-MG verificaram em 42 amostras analisadas de alface a presença de $14,2 \%$ de Entamoeba coli, 4,7\% de Entamoeba histolytica, 2,3\% de Schistosoma spp, 9,5\% de Strongyloides spp, 4,7\% de larvas de ancylostomideos e $2,3 \%$ de ovos de ancylostomideos, sendo a Entamoeba coli a espécie mais encontrada. GARCIA et al. (2005) na cidade de Guarapuava-PR analisaram133 amostras de hortaliças de produtores rurais, observando $9,7 \%$ de Ascaris spp., 9,7\% de Ancilostomatídeos, 1,5\% de Enterobius vermicularis, $0,8 \%$ de Strongyloides spp., 3,8\% de Entamoeba spp. e 0,8\% de Giardia spp. Evidenciando uma prevalência de Ascaris lumbricoides. Ambos os estudos não apresentaram a Entamoeba ssp. como enteroparasita predominante nas análises.

Insta observar que as hortaliças foram adquiridas na feira livre da cidade de Governador Valadares, porém, todas advêm da zona rural de Caratinga, cidade localizada a $121 \mathrm{~km}$ de Governador Valadares, segundo dados do IBGE (2016). SILVA \& GONTIJO (2016) em seu trabalho observaram que a água utilizada para irrigação das hortaliças estudadas era proveniente de açudes ou poços e constataram contaminação por coliformes fecais em todas.

Outro fator que afeta a qualidade dos produtos é a contaminação com fezes 
humanas, MESQUITA et al. (1999) afirmam que essa contaminação tem se tornado uma questão preocupante e vem sendo utilizada como fonte de estudo no Brasil. Os dados apresentados neste trabalho e em outros corroboram com a afirmação que parasitoses intestinais tem se tornado um grave problema de saúde pública no país (SILVA \& GONTIJO , 2012). Tais fatores podem ter influenciado na contaminação evidenciada pela pesquisa, principalmente a utilização de água não tratada e a manipulação nos postos de vendas, como afirmam TAKAYANAGUI et al. (2001) em estudo.

Os resultados deste estudo indicam a presença de enteroparasitas em $90 \%$ das amostras de alface (Lactuca sativa) coletadas na feira livre da cidade de Governador Valadares, Minas Gerais, estando de acordo com outros estudos realizados por todo o território brasileiro. Tal problemática evidencia que independente da região o consumidor está sujeito a consumir alfaces de baixo índice higiênico, podendo assim estar colocando em risco a sua saúde, pois, a hortaliça nesse estado é uma grande veiculadora de protozoários e helmintos.

No cultivo de hortaliças, pode ocorrer contaminação fecal de forma direta ou indireta; a forma direta ocorre quando são utilizados como fertilizantes excretas humanos ou de animais in natura; a forma indireta se caracteriza pelo uso de águas poluídas com matéria fecal, podendo ser na irrigação ou na lavagem das verduras. Essas lavagens são as que mais freqüentemente podem contaminar as hortaliças na fonte de produção, durante o preparo para venda (BONILHA, 1994). Os alimentos comercializados nas feiras livres estão mais expostos a contaminação devido ao baixo controle bromatológico ou manipulação inadequada que consequentemente pode levar a veiculação de microrganismos.

A exposição ao ar livre predispõe o alimento a contaminação por microrganismos e insetos veiculadores de formas parasitárias, devido ao crescimento da poluição (XAVIER, 2009). Segundo OLIVEIRA \& PEREZ (2014), "Apesar de os resultados mostrarem contaminações por enteroparasitoses nas hortaliças, 0 benefício que esses alimentos trazem em sais minerais e vitaminas se sobressaem à contaminação. Faz-se necessária a conscientização da população que consome esses vegetais para que promovam a correta higienização para o consumo".

\section{CONCLUSÃO}

De acordo com o trabalho realizado conclui-se que as alfaces comercializadas na feira livre de Governador Valadares apresenta baixo padrão de higiene que pode ser evidenciado pela presença de formas parasitária originárias de fezes humanas.

Os parasitas intestinais mais encontrados foram protozoários como a Giardia lamblia e Entamoeba histolytica que estavam presentes em boa parte das mostras. Ovos e larvas de helmintos também foram encontrados, mas em menor proporção. Desta forma é necessária a aplicação de um programa de educação sanitária para os agricultores visando a redução do índice de contaminação das alfaces, e também para os consumidores, objetivando minimizar a problemática do presente estudo que é relacionado a transmissão de parasitoses ao homem. Além disso, é necessário frisar a necessidade de fazer uma correta lavagem das folhas antes de consumi-las, para que o consumidor não venha a ingerir tais enteroparasitas.

\section{REFERÊNCIAS}


ACOSTA M. B.; DUARTE, L. G. Pesquisa da existência de bactérias Gram negativas endofíticas potencialmente patogênicas para o homem em hortaliças provenientes de cultivos orgânicos. Revista Venezolana de Endocrinologia y Microbiología Metabolismo, Mérida, v. 13, n. 1, p. 14-24, março 2015.

ALVES, A. S.; NETO, A. C.; ROSSIGNOLI, P. A. Parasitos em alface-crespa (Lactuca sativa I.), de plantio convencional, comercializada em supermercados de Cuiabá, Mato Grosso, Brasil. Goiás. Revista de Patologia Tropical, v.42, abriljunho, 2013.

ARBOS, K.A.; FREITAS, R.J.S.; STERTZ, S.C; CARVALHO, L.A Segurança alimentar de hortaliças orgânicas: aspectos sanitários e nutricionais. Ciência e Tecnologia de Alimentos, Campinas, v.30, supl.1: 215-220, mai/2010. Disponível em:<http://www.scielo.br/scielo.php?script=sci_arttext\&pid=S0101206120100005000 33\&lng=en\&nrm=iso> Acesso em 02 mai. 2017. http://dx.doi.org/10.1590/S010120612010000500033.

BELINELO, V.; GOUVÊIA, M. I.; COELHO, M. P.; ZAMPROGNO, A. C.; FIANCO, B. A.; OLIVEIRA, L. G. A.. Enteroparasitas em hortaliças comercializadas na cidade de São Mateus, ES, Brasil. Umuarama. Arquivo Ciências Saúde Unipar, v. 13, n. 1, p. 33-36, janeiro-abril, 2009.

BONILHA, P.R.M.; FALCÃO, D.P. Ocorrência de enteropatógenos em alfaces e suas águas de irrigação, São Paulo. Revista Alimentos e Nutrição, v.05, p.87-97, 1993/94.

COSTA, C. P.; SALA, F. C. A evolução da alfacicultura brasileira. Horticultura Brasileira, Brasília, DF, v. 23, n. 1, 2005.

FARIA, M.; MAIA, M.C.; CALDEIRA, F.V.N.D.; OLIVEIRA, J.P. Frequência de enteroparasitos em amostras de alfaces (Lactuca sativa) comercializadas em feiras livres na cidade de Ipatinga, Minas Gerais. Ipatinga. Revista Digital de Nutrição, V. 2 - N. 2 - Fevereiro-Julho, 2008.

FREITAS, A.; KWIATKOWSKI, A.; NUNES, S. C.; SIMONELLI, S. M.; SANGIONI, L. A. Avaliação parasitológica de alfaces (Lactuca sativa) comercializadas em feiras livres e supermercados do município de Campo Mourão, Estado do Paraná. Maringá. Acta Scientiarum. Biological Sciences. v. 26, no. 4, p. 381-384, 2004.

GARCIA, J.L.; ONO, L. M.; PERETTI, J.; ZULPO, D. L. Ocorrência de helmintos e protozoários em hortaliças cruas comercializadas no município de Guarapuava, Paraná, Brasil. Londrina. Semina: Ciências Agrárias, v. 26, n. 4, p. 543-546, outubro-dezembro, 2005.

PREFEITURA MUNICIPAL DE GOVERNADOR VALADARES. História da Cidade. Disponível em: http://www.valadares.mg.gov.br/detalhe-da-materia/info/historia-dacidade/12094. Acesso em 10 set. 2016.

HENRIQUE, C.; PARISI, M. C.; PRATI, P. CONTAMINAÇÃO MICROBIOLÓGICA PÓS-COLHEITA. Pesquisa e Tecnologia. Disponível em: < 
http://www.aptaregional.sp.gov.br/acesse-os-artigos-pesquisa-etecnologia/2014/janeiro-junho/1545-contaminacao-microbiologica-poscolheita/file.html ISSN 2316-5146 >. Acesso em 10 set. 2016.

IBGE. Resultados do censo 2016. Acesso em: 15 Set. 2016.

LUZ, J.; CÂMARA, H. C. F.; LIMA, D. V. P.; SILVA, M. H. R.; COSTA, E. L.; ZELENOY, C. K. G. Avaliação da contaminação parasitária em alfaces (Lactuca sativa) comercializadas em feiras livres na região da Grande Natal, Rio Grande do Norte. Ceará. Nutrivisa, Vol. 1, Núm. 2 , pág. 16-19, 2014.

MAISTRO, L. Alface Minimamente Processada: Uma Revisão. Revista Nutrição, Campinas, p. 219-224, set/dez., 2001.

MAROUELLI, W. A; MALDONADE, IR; BRAGA, M.B; SILVA, H.R. Qualidade e segurança sanitária da água para fins de irrigação. Circular Técnica, OUT. 2014. Disponível em: https://www.infoteca.cnptia.embrapa.br/bitstream/doc/1007665/1/CT134.pdf . Acesso em 20 set. 2016.

MESQUITA, V.C.L.; SERRA, M.B.; BASTOS, O.M.P.; UCHÔA, C.M.A.; Contaminação por enteroparasitas $\mathrm{cm}$ hortaliças comercializadas nas cidades de Niterói e Rio de Janeiro, Brasil. Revista da Sociedade Brasileira de Medicina Tropical, v. 32, n. 4, p. 363-366, 1999.

NEVES, D. P. Parasitologia Humana. 11. ed. São Paulo: Atheneu, 2011.

OLIVEIRA C. A. F, GERMANO, P. M. L 1992. Estudo da ocorrência de enteroparasitas em hortaliças comercializadas na região metropolitana de São Paulo, SP, Brasil, I Pesquisa de helmintos. Revista Saúde Publica, 26 (4): 283-289.

OLIVEIRA, A.; PEREZ, L. Contaminação de enteroparasitas em folhas de alface (Lactuca sativa) e agrião (Nasturtium officinalis) em duas hortas comerciais de foz do Iguaçu, estado do Paraná, Brasil. Rio de Janeiro. Revista Eletrônica Novo Enfoque, v. 18, n. 18, p. $109-124,2014$.

PIRES, D.R; THOMÉ, S.M.G; COELHO, P.S.J; SANTOS, H.A; FRECHETTE, M.F; ABBOUD, L.C.S. Avaliação parasitológica de alfaces (Lactuca sativa) comercializadas no município do Rio de Janeiro (RJ) Semina: Ciências Biológicas e da Saúde, Londrina, v. 35 , n. 1, p. 35-48, jan./jun. 2014. Disponivel em: www.uel.br/revistas/uel/index.php/seminabio/article/view/15268/15829 DOI: 10.5433/1679-0367 Acesso em 03 NOV.2016

RODRIGUES,P. A importância nutricional das hortaliças, Cores e Sabores. Hortaliças em Revistas, 2ª Edição - Março / Abril de 2012. Disponível em: < https://www.embrapa.br/documents/1355126/2250572/revista_ed2.pdf/74bbe524a730-428f-9ab0-ad80dc1cd412>. Acesso em 20 set. 2016.

SILVA, M.G; GONTIJO, E.E.L. Avaliação parasitológica de alfaces (Lactuca sativa) 
comercializadas em supermercados e feiras livres do município de Gurupi, Tocantis. Revista Científica do ITPAC, Araguaína, v.5, n.4, Out. 2012. Disponível em: http://www.itpac.br/arquivos/Revista/54/6.pdf. ISSN 1983-6708 Acesso em 03 Nov.2016

SILVA, A.F.S; LIMA, C.A; QUEIROZ, J.J.F; JÁCOME, P.R.L.A; JUNIOR, A.T.J. Análise bacteriológica das águas de irrigação de horticulturas. Ambiente \& Água An Interdisciplinary Journal of Applied Science ISSN 1980-993X - doi:10.4136/1980993X, Mar. 2016 Disponivel em: http://www.scielo.br/pdf/ambiagua/v11n2/1980993X-ambiagua-11-02-00428.pdf Acesso em 03 Nov. 2016

SOARES, B.; CANTOS, G. A. Detecção de estruturas parasitárias em hortaliças comercializadas na cidade de Florianópolis, SC, Brasil. Revista Brasileira de Ciências Farmacêuticas, São Paulo, v. 42, n. 3, p. 455-460, Set. 2006. Disponível em:http://www.scielo.br/scielo.php?script=sci_arttext\&pid=S15169332200600030001 5\&lng=en\&nrm=isolSSN1516-9332. Acesso em 03 Nov. 2016.

TAKAYANAGUI, O.; OLIVEIRA, C.D.; BERGAMINI, A.M.M.; CAPUANO, D.M.; OKINO, M.H.T.; CASTRO E SILVA, A.A.M.C.; et al.,; Fiscalização de verduras comercializadas no município de Ribeirão Preto, SP. Revista da Sociedade Brasileira de Medicina Tropical, Uberaba, v. 34, n. 1, p. 37-41, Fev. 2001. Disponível em: <http://www.scielo.br/scielo.php?script=sci_arttext\&pid=S003786822001000100006\& Ing=en\&nrm=iso>. Acesso em 03 Nov. 2016.

XAVIER, A.Z.P.; VIEIRA, G.D.G.; RODRIGUES, L.O.M.; VALVERDE, L.O.; PEREIRA, V.S. Condições higiênico-sanitárias das feiras-livres do município de Governador Valadares. Governador Valadares - MG: UNIVALE, 2009. Trabalho de Conclusão de Curso de nutrição, Faculdade de Ciência da Saúde - FACS, Universidade Vale do Rio Doce, 2009. 